\title{
Rubber composites cured with sulphur and peroxide and incorporated with strontium ferrite
}

\author{
JÁN KRUŽELÁK ${ }^{1, *}$, RASTISLAV DOSOUDIL ${ }^{2}$, RICHARD SÝKORA ${ }^{1}$ and IVAN HUDEC ${ }^{1}$ \\ ${ }^{1}$ Department of Plastics and Rubber, Faculty of Chemical and Food Technology, Slovak University of Technology, \\ 81237 Bratislava, Slovakia \\ ${ }^{2}$ Department of Electromagnetic Theory, Faculty of Electrical Engineering and Information Technology, Slovak \\ University of Technology, 81219 Bratislava, Slovakia
}

MS received 18 March 2016; accepted 30 May 2016

\begin{abstract}
In the present work, rubber magnetic composites were prepared by incorporation of strontium ferrite into rubber matrices based on natural rubber (NR) and acrylonitrile-butadiene rubber (NBR). Sulphur, peroxide and mixed sulphur/peroxide curing systems were introduced in cross-linking of rubber matrices. The aim was to investigate the influence of curing system composition on physical-mechanical, thermo-physical and magnetic properties of prepared rubber composites and the curing process. Then, the determination of cross-link density and the structure of cross-links were under consideration. The achieved results showed that all investigated parameters were changed depending on the composition of curing system, but also on the type of rubber matrix. While the tensile strength of composites based on NR increased with increasing amount of sulphur in mixed curing systems, in case of composites based on NBR, the highest value of tensile strength reached the value of the sample cured with equivalent ratio of sulphur and peroxide. On the other hand, thermo-physical and magnetic characteristics were found not to be dependent on the curing system composition. The results revealed that not only the composition of curing system, but also the type of rubber matrix plays an important role when preparing the final materials.
\end{abstract}

Keywords. Rubber composites; magnetic filler; sulphur curing; peroxide curing; cross-link density.

\section{Introduction}

Besides classical applications of rubber products in tyres, conveyer belts and other products from technical rubber, in the recent years a rapid interest in utilization of rubber materials in the form of sensors, switches, biometric sensing devices or shielding materials of magnetic and electromagnetic fields has been shown. These applications require new types of rubber compounds with incorporated untraditional fillers as active elements. The possible way of such materials preparation is application of magnetic fillers.

Ferrites are a class of technologically important magnetic materials with strong magnetocrystalline anisotropy and high values of magnetic characteristics (mainly coercivity and remanent magnetic induction) [1-3]. Besides this, they exhibit good chemical stability with a high resistance to solvents, salts, lubricants, alkalis, harmful gases, soft acids and atmospheric effects too. By incorporation of magnetic polycrystalline ferrites into various rubber matrices it is possible to prepare composite materials referred to as rubber magnets [4-7]. Rubber composites with magnetic fillers are able to sensitively respond to vibrations and absorb oscillations of various wavelengths. They can also change magnetic and mechanical properties at different forms of strain. Therefore they have been found to be applied in d.c.-motors, new

*Author for correspondence (jan.kruzelak@stuba.sk) types of recording appliances and magnetic screeners, and also in microwave and radar technology, biotechnology and other technological applications [8-10].

The application properties of the final rubber compounds are achieved in the process of vulcanization or curing. During this process, plastic rubber compound changes into highly elastic final product by forming a three-dimensional crosslinked network structure inside the rubber matrix. Chemical cross-links between rubber chains are formed by introduction of different vulcanization systems. Sulphur and peroxide vulcanization systems are nowadays the most frequently introduced in cross-linking of rubber matrices $[11,12]$. The application of sulphur curing systems leads to the forming of sulphidic bridges with various number of sulphur atoms (monososulphidic C-S-C, disulphidic $\mathrm{C}-\mathrm{S}_{2}-\mathrm{C}$ and polysulphidic cross-links $\mathrm{C}-\mathrm{S}_{x}-\mathrm{C}$, where $x$ can vary from 3 to 6 ) between elastomer chains [13].

Applying peroxide systems in cross-linking of elastomers, covalent carbon-carbon cross-links between rubber chains are formed [14]. C-C bonds have higher dissociation energy in comparison with sulphidic cross-links; therefore peroxidecured elastomers exhibit high thermal stability and good resistance to thermo-oxidative ageing, but also good electrical properties or low compression set [15-17]. The disadvantages, when compared with sulphur-cured elastomers, are their inferior dynamic properties and worse tensile and tear strength performance. 
In our pervious works, rubber magnetic composites were prepared by application of either sulphur [18] or peroxide curing systems [19], which changed the content of magnetic filler. The main aim of the work by Kruželák et al [20] was investigation and comparison of properties of rubber composites based on natural rubber (NR) cured with both curing systems. The achieved results showed that the presence of both curing systems leads to the preparation of composite materials with good magnetic characteristics and also suitable physical-mechanical properties, although these properties were significantly dependent on the type of vulcanization system and of course on the content of magnetic filler.

In this work, rubber magnetic composites based on NR and acrylonitrile-butadiene rubber (NBR) were prepared in the presence of sulphur, peroxide and mixed sulphur/peroxide curing systems, while the content of magnetic filler was kept constant. A combination of both curing systems in crosslinking of elastomers should combine the patterns of sulphidic bridges and $\mathrm{C}-\mathrm{C}$ linkages. As both vulcanization systems have advantages but also drawbacks, the main aim was to suppress the main negatives of both curing systems and possibly to highlight their benefits.

Two types of elastomers were chosen for the experiments. NR has unique properties, which distinguish it from other synthetic rubber. It is an unsaturated, non-polar elastomer with highly stereo-regular structure, containing $99.9 \%$ of cis-1,4-isoprene structural units. Due to this, it is a crystalizing elastomer with almost ideal elastic and hysteresis properties.

NBR is a synthetic unsaturated co-polymer, consisting of cis-, trans-1,4 and 1,2-butadiene structural units and polar acrylonitrile structural unit, which ranks it among polar elastomers. Due to the irregularity of macromolecular chains, it is a non-crystallizing elastomer with good resistance to non-polar solvents.

\section{Experimental}

\subsection{Materials}

NR (SMR5, Mardec, Malaysia) and synthetic NBR (SKN 3345 , content of acrylonitrile 31-35\%, Sibur International, Russia) were used as rubber matrices. The structural units of both type rubbers are presented in figures 1 and 2 . Strontium ferrite $\mathrm{SrFe}_{12} \mathrm{O}_{19}$ (type FD 8/24) supplied by

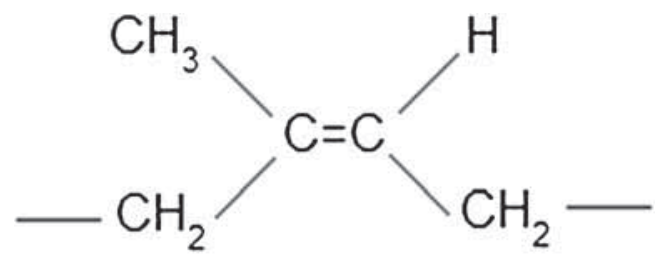

\section{Cis-1,4-polyisoprene}

Figure 1. Structural unit of natural rubber.

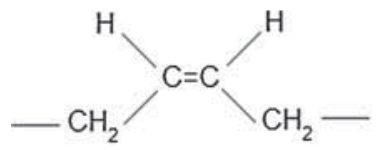

Cis-1,4-polybutadiene<smiles>C=CC(C)CC</smiles>

1,2-Polybutadiene

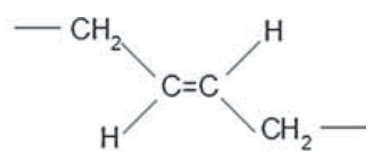

Trans-1,4-polybutadiene<smiles>CCC(C)C#N</smiles>

Acrylonitrile
Figure 2. Structural units of acrylonitrile-butadiene rubber.

Magnety, Světlá Hora, Czech Republic, was used as the magnetic filler. The peroxide curing system consisted of dicumyl peroxide (DCP; Merck Schuchardt OHG, Germany) as the peroxide curing agent and ethylene glycol dimethacrylate (EGDA; Merck Schuchardt OHG, Germany) as a co-agent. The sulphur curing system consisted of zinc oxide (Slovlak, Košeca, Slovakia) and stearic acid (Setuza, Ústí nad Labem, Czech Republic) as activators, N-cyclohexyl-2benzothiazole sulphenamide (CBS; Duslo, Šal'a, Slovakia) as an accelerator and sulphur (Siarkopol, Tarnobrzeg, Poland) as the curing agent.

\subsection{Methods}

2.2a Preparation and curing of rubber compounds: The rubber compounds were prepared in two mixing steps in a laboratory Brabender mixer. In the first step $\left(9 \mathrm{~min}, 90^{\circ} \mathrm{C}\right)$, the rubber and the filler were compounded. In the second step $\left(4 \mathrm{~min}, 90^{\circ} \mathrm{C}\right)$, the curing system was introduced. Five types of rubber formulations were tested, in which the first rubber compound was prepared only by applying peroxide curing system and the last one only with sulphur curing system. In the remaining three types of rubber formulations, the mutual ratio of sulphur to peroxide was uniformly changed, so that the amount of both curatives in all rubber compounds was kept constant. Similarly, the amount of co-agent EGDA in peroxide curing system and accelerator CBS in sulphur curing system were also proportionally changed. Rubber compounds used in the study are identified according to the content of sulphur and peroxide system they contain and their ratio. The rubber compound cured in only peroxide system is identified as S0-P1.5 and the rubber compound cured only with sulphur system is recognized as S1.5-P0. The content of magnetic filler was kept constant in all rubber compounds -60 PHR. The composition of rubber compounds and their designation are summarized in table 1 .

The curing characteristics of rubber compounds were investigated from the corresponding curing isotherms measured using a Rheometer Monsanto R100 at $160^{\circ} \mathrm{C}$. The curing process was performed at $160^{\circ} \mathrm{C}$ for the optimum curing time under a pressure of $15 \mathrm{MPa}$ using a hydraulic press 
Table 1. Composition of rubber compounds and their designation.

\begin{tabular}{lccccc}
\hline Content & PHR & PHR & PHR & PHR & PHR \\
\hline NR, NBR & 100 & 100 & 100 & 100 & 100 \\
ZnO & 3 & 3 & 3 & 3 & 3 \\
Stearic acid & 2 & 2 & 2 & 2 & 2 \\
Ferrite & 60 & 60 & 60 & 60 & 60 \\
Sulphur & 0 & 0.5 & 0.75 & 1 & 1.5 \\
CBS & 0 & 0.25 & 0.375 & 0.5 & 0.75 \\
DCP & 1.5 & 1 & 0.75 & 0.5 & 0 \\
EGDA & 0.75 & 0.5 & 0.375 & 0.25 & 0 \\
Sample & S0-P1.5 & S0.5-P1 & S0.75-P0.75 & S1-P0.5 & S1.5-P0 \\
\hline
\end{tabular}

Fontijne. Finally, thin sheets $\left(15 \times 15 \mathrm{~cm}^{2}\right.$, thickness $\left.2 \mathrm{~mm}\right)$ of cured rubber compounds were obtained.

2.2b Determination of cross-link density of composites: Determination of cross-link density $v$ is based on equilibrium swelling of samples in suitable solvent. Two different solvents were used. Samples of composites based on NR were swelled in xylene, while samples of composites based on NBR were swelled in acetone within the time until the equilibrium swelling was reached. The experiments were carried out at laboratory temperature and the swelling time was equal to $30 \mathrm{~h}$. The Krause-modified Flory-Rehner equation for filled vulcanizates [21] was introduced to calculate the cross-link density based upon the previously obtained equilibrium swelling degree:

$$
v=-\frac{V_{\mathrm{r} 0}}{V_{\mathrm{S}}} \frac{\ln \left(1-V_{\mathrm{r}}\right)+V_{\mathrm{r}}+\chi V_{\mathrm{r}}^{2}}{V_{\mathrm{r}}^{1 / 3} V_{\mathrm{r} 0}^{2 / 3}-0.5 V_{\mathrm{r}}}
$$

where $v$ is the cross-link density $\left(\mathrm{mol} \mathrm{cm}^{-3}\right), V_{\mathrm{r} 0}$ the volume fraction of rubber in equilibrium swelling sample of vulcanizate in the absence of fillers, $V_{\mathrm{r}}$ the volume fraction of rubber in equilibrium swelling sample of filled vulcanizate, $V_{\mathrm{S}}$ the molar volume of solvent (for xylene $=123.45 \mathrm{~cm}^{3} \mathrm{~mol}^{-1}$, for acetone $\left.=73.519 \mathrm{~cm}^{3} \mathrm{~mol}^{-1}\right)$ and $\chi$ the Huggins interaction parameter (for NR-xylene $\chi=0.4106$, for NBRacetone $\chi=0.3692)$.

2.2c Determination of physical-mechanical properties of composites: The tensile properties of tested composites were measured using a Zwick Roell/Z 2.5 appliance at crosshead speed of $500 \mathrm{~mm} \mathrm{~min}^{-1}$ and laboratory temperature in accordance with the valid technical standards, on the double side dumbbell-shaped test specimens (width $6.4 \mathrm{~mm}$, length $8 \mathrm{~cm}$ and thickness $2 \mathrm{~mm}$ ). The hardness was measured using a durometer and the unit was expressed in Shore A.

2.2d Evaluation of thermo-physical properties of composites: An Isomet appliance was applied in order to evaluate thermophysical characteristics of prepared materials. The measurement is based on the analysis of time dependence of thermal response to the impulses of the thermal flow into the analysed material. The thermal flow is generated by scattered electric discharge in the probe resistor, which is connected with the analysed material through thermal conductivity. The temperature of the resistor is scanned by a semiconductive detector.

2.2e Evaluation of magnetic characteristics of composites: Magnetic characteristics of prepared magnetic composites were evaluated at room temperature and the maximum coercivity $H_{\mathrm{m}}=750 \mathrm{kA} \mathrm{m}^{-1}$. For this purpose, a magnetometer TVM-1 (Vúzort, Praha, Czech Republic) was used. The basic principle of measurement is the induction method of scanning of scattering magnetic flux $\Phi$ induced by a magnetic vibrating sample. The magnetic field is generated by means of two cores of a Weiss electromagnet at a minimum distance of poles adapters of $7.5 \mathrm{~mm}$. The induced tension proportional to time dependence of magnetic flux in the sample is scanned with the system of four small cores. The cores eliminate the influence of time instability of electromagnet magnetic fields and the change of magnetic flux is directly proportional to magnetic induction $B$. The specimens for the magnetic characteristics evaluation were of prism shape $\left(8 \times 4 \times 4 \mathrm{~mm}^{3}\right)$.

\section{Results and discussion}

\subsection{Influence of curing systems on curing process of rubber compounds}

The values of curing characteristics were determined from the corresponding curing isotherms. The scorch time $t_{s 1}$ of both NR- and NBR-based rubber compounds showed increasing tendency with increasing amount of sulphur and decreasing amount of peroxide in the applied curing systems. As seen in figure 3, rubber compounds based on NBR exhibited higher values of scorch time, except for the sample

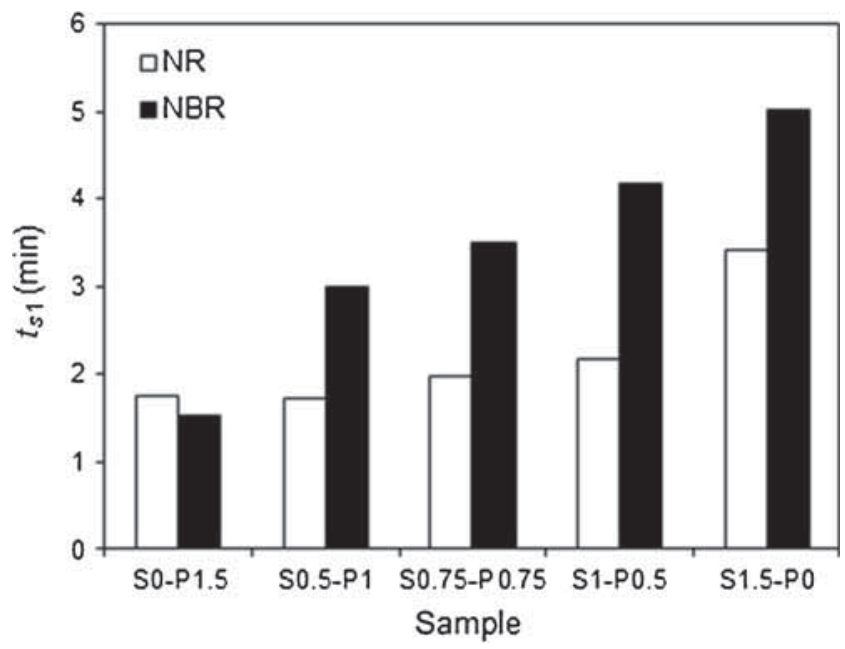

Figure 3. Influence of curing system composition on scorch time $t_{s 1}$ of rubber compounds. 
cured only with peroxide system (S0-P1.5). The sulphur vulcanization is a complex process. Sequences of subsequent and parallel chemical reactions proceed during this process in several stages. Generally, transition complexes formed from activators, accelerators and sulphur are formed in the first stage of sulphur curing. In this time, called scorch time or induction period, cross-linking does not take place yet. The length of this period depends mainly on the type and amount of accelerator. CBS belongs to sulphenamides types of accelerators, which are characterized by long induction period, which is an advantage in processing of rubber materials. By contrast, the regulation of scorch time in peroxide curing of rubbers is quite complicated, because peroxide radical species that are formed from peroxide decomposition at the vulcanization temperature immediately react with rubber chains to form cross-links. Induction period can be influenced mainly by the type of peroxide and its ability to dissociate into free radicals at vulcanization temperature. The process can be hardly affected only by the change in peroxide concentration or by using radical reaction inhibitors, because their presence in the rubber mixture can cause lowering of the cross-linking yield and efficiency. Thus, the reduction of accelerator CBS in sulphur curing system seems to be the main reason for the decrease of the scorch time in the prepared rubber formulations.

From figure 4 it becomes evident that for rubber compounds based on NR the shortest time for optimum curing $t_{c 90}$ was required for the sample cured only with sulphur system (S1.5-P0), while the sample cured only with peroxide system (S0-P1.5) required three times longer optimum cure time. The optimum cure time of rubber compounds with mixed sulphur/peroxide systems almost linearly shortened with increasing content of sulphur and decreasing content of peroxide. By contrast, the values $t_{c} 90$ of rubber compounds based on NBR passed over a slight maximum at the equivalent ratio of sulphur and peroxide (S0.75-P0.75); subsequently a decrease of optimum cure time was recorded (figure 4). Shorter scorch time and also optimum cure time of rubber compounds based on NR in comparison with the corresponding characteristics of rubber compounds based on NBR indicate that the curing process of materials based on NR proceeds faster. The reason can be attributed to the presence of higher amount of reactive groups (mainly double bonds and allylic hydrogens) present in the molecular structure of natural rubber, which are able to react more rapidly with functional groups of curing agents to form cross-links.

\subsection{Influence of curing systems on cross-link density}

Although the curing process of rubber compounds based on NBR proceeded more slowly when compared with those based on NR, composites based on synthetic NBR showed much higher cross-link density $v$ (figure 5). The sample cured only with peroxide system (S0-P1.5) showed the highest cross-link density followed by the sample cured with only sulphur system (S1.5-P0). The lowest degree of crosslinking was exhibited by the sample cured at the equivalent ratio of sulphur and peroxide (S0.75-P0.75). Although the differences in the $v$ values of composites based on NR were much lower, it can also be stated that samples cured only with sulphur (S1.5-P0) or peroxide system (S0-P1.5) showed slightly higher cross-linking degree in comparison with the samples cured with mixed vulcanization systems. The biggest difference between the cross-link densities of NR- and NBR-based composites was observed in the case of samples cured only with peroxide system (S0-P1.5). As seen in figure 5, the cross-link density of NBR-based composite S0-P1.5 was nearly five times higher compared with the equivalent composite based on NR.

Cross-linking of rubbers with organic peroxides is a radical process during which peroxide molecules first undergo homolytic cleavage to form primary radicals. The primary radicals can be eventually fragmented into secondary reactive species at high temperatures. The peroxide radicals

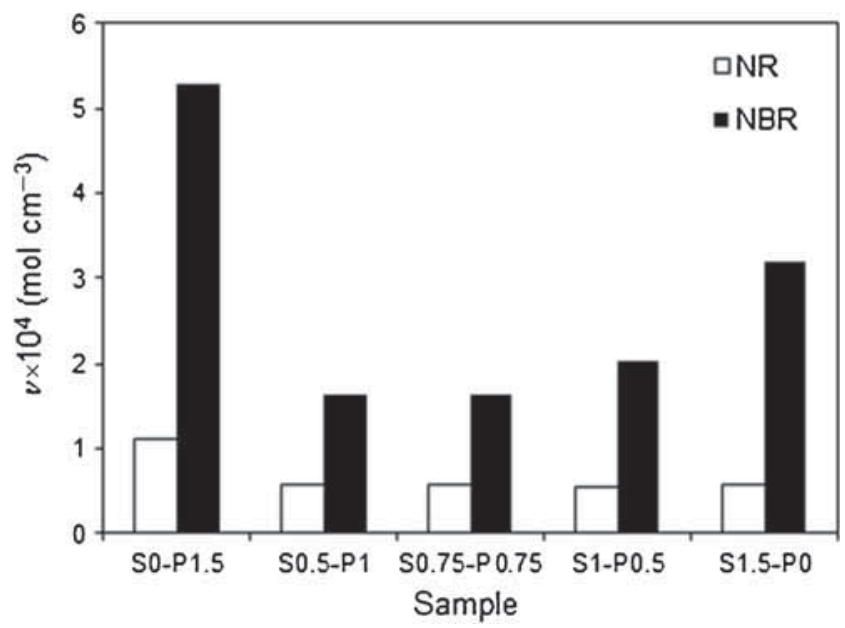

Figure 5. Influence of curing system composition on cross-link density $v$ of composites.
Figure 4. Influence of curing system composition on optimum cure time $t_{c} 90$ of rubber compounds.

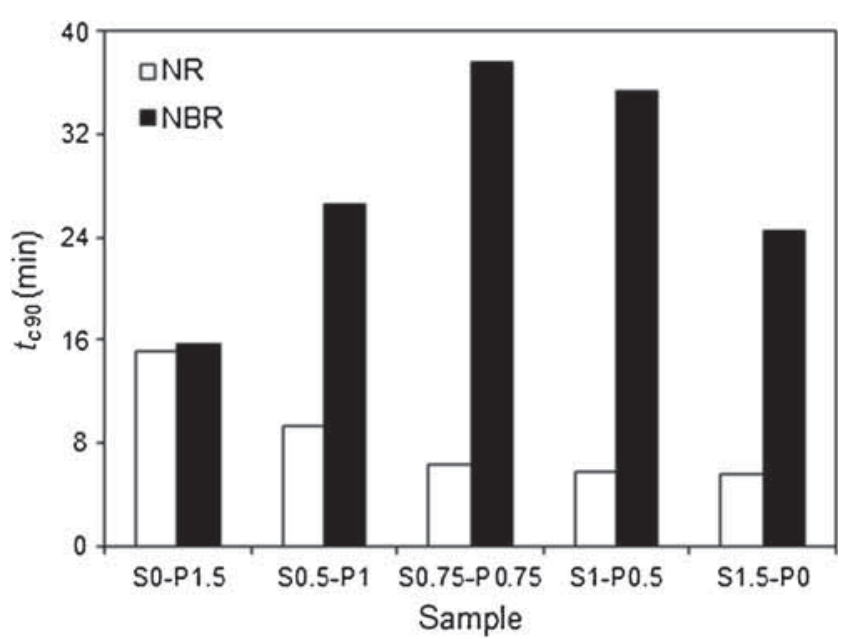


subsequently react with macromolecules of rubber to form cross-links between them. Peroxide radicals could potentially react with rubbers by abstraction of hydrogen from their macromolecular chains or by addition to a double bond of unsaturated rubbers [22,23]. The elastomer radicals that are formed during these reactions subsequently mutually recombine to form cross-links. In peroxide crosslinking of NR, the abstraction of allylic hydrogens by peroxide reactive species has been suggested to be the predominant mechanism for elastomer radical formation. By recombination of two elastomer radicals, the cross-link between them is formed (figure 6). It was experimentally concluded that during peroxide curing of NR with DCP, this peroxide forms one mole of cross-links per mole of peroxide; hence the peroxide efficiency equals to 1 [24,25].

It was also suggested that the elastomer radicals can participate in addition reactions besides mutual recombination reactions. The occurrence of addition reactions becomes more obvious during cross-linking of polybutadiene and its copolymers with higher amount of 1,2-butadiene structural units. During peroxide cross-linking of polybutadiene, it has been proposed that peroxide radicals can react by hydrogen atoms abstraction, during which more reactive macroradicals than in the case of NR are formed, and also by addition reactions to the double bonds. The formed macroradicals can undergo addition reactions to the double bonds in rubber chains in addition to the mutual coupling reactions (figure 7). The chain character of addition reactions results in high cross-linking efficiency, i.e., 10-50 for polybutadiene depending on the microstructure of polybutadiene. High cross-linking efficiency can be observed mainly by peroxide cross-linking of polybutadiene and its copolymers with high amount of 1,2-butadiene units, suggesting that the pendant vinyl units participate in addition reactions more easily than internal double bonds [24]. The above-outlined aspects seem to be the reason for much higher cross-link density of peroxide-cured composite based on NBR in comparison with equivalent composite based on NR.

It is possible to observe in figure 5 that various degrees of cross-linking are found in structures of NR and NBR composites cured with sulphur system (S1.5-P0), although the difference between them was not as high as in the previous
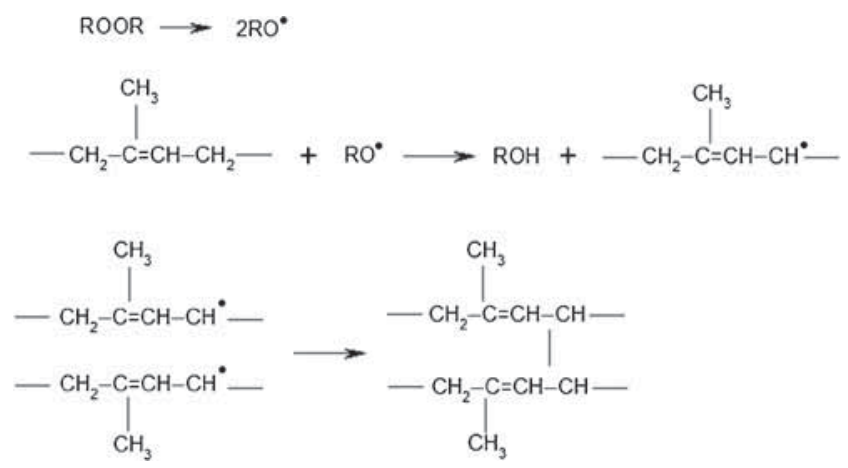

Figure 6. Peroxide cross-linking of natural rubber. case. The chemistry of sulphur vulcanization of rubber is very intricate and still not fully understood. A complicated sequence of reactions occurs, many of which are competitive and most of which involve equilibria. It is supposed that in the first stage, the interaction of activators (stearic acid with zinc oxide) forms a salt that gives intermediate transition complexes with the accelerator. The complex is more effective in activating sulphur, leading to the formation of an active sulphurating agent. The next step is generation of pendant groups on the rubber chain. The polysulphidic thiol (sulphur with accelerator) becomes attached to the allylic position on the rubber chain. The last step is the generation of a polysulphidic bridge with the release of the accelerator reaction product. Because of low $\mathrm{S}-\mathrm{S}$ bonding energy of approximately $270 \mathrm{~kJ} \mathrm{~mol}^{-1}$ (for comparison $\mathrm{C}-\mathrm{C}$ bonding energy is $350 \mathrm{~kJ} \mathrm{~mol}^{-1}$ ), the polysulphidic bridges change more and more into di- and monosulphidic types by thermal scission during the vulcanization time at vulcanization temperature (figure 8) [26,27]. The functional groups active in sulphur vulcanization of unsaturated rubbers are double bonds and reactive hydrogens present in their structural units. Compared with NBR, NR exhibits higher amount of reactive centres; therefore it could be supposed that the composite based on NR should also have higher cross-link density. But seeing the results in figure 5, the reverse tendency is observed. Probably, what contributes to higher cross-link density of the composite based on NBR is some addition reactions of macromolecular radicals, formed also during sulphur curing, on the inchain double bonds and mainly on the side-chain vinyl units of NBR, thus making the curing process more efficient.

In both NR- and NBR-based composites, the lowest crosslinking degree is exhibited by composites cured in the presence of equivalent ratio of sulphur and peroxide (S0.75$\mathrm{P} 0.75)$. The possible explanation of this might be some competitive reactions, which may consume free peroxide radical species and/or sulphur fragments, running simultaneously with the main cross-linking reactions.
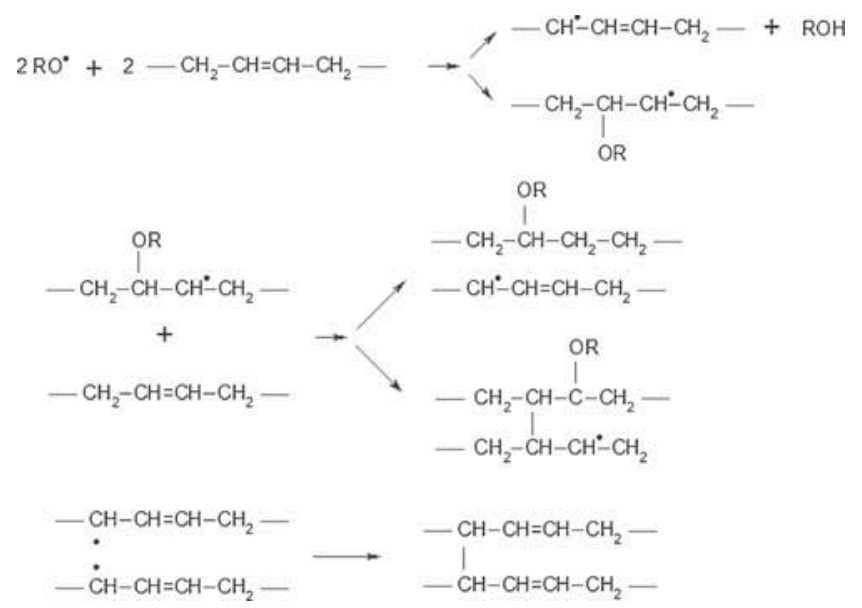

Figure 7. Peroxide cross-linking of butadiene-type rubbers. 


\subsection{Influence of curing systems on physical-mechanical properties}

The values of physical-mechanical properties of prepared composites are graphically illustrated in figures 9-11. The hardness of composites is in close connection with the dependence of cross-link density. It becomes evident from figures 5 and 9 that higher cross-link density of composites based on NBR is reflected in higher hardness of equivalent composites. The highest hardness of both NR- and NBR-based composites is shown by samples cured only with peroxide system (S0-P1.5) with the highest cross-linking degree, while the lowest hardness is exhibited by composites cured at equivalent ratio of sulphur and peroxide (S0.75-P0.75) with the

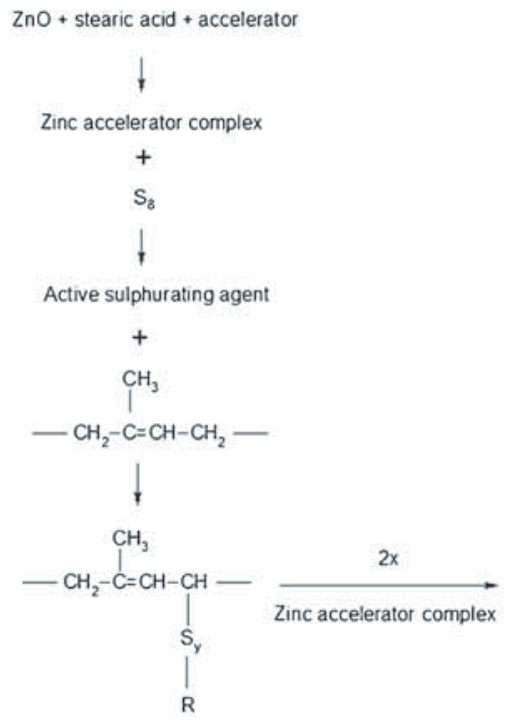

$\mathrm{R}$ (accelerator residue)

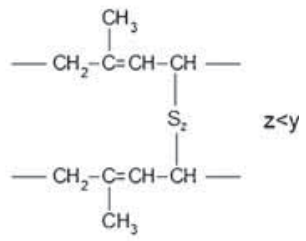

Figure 8. Reaction mechanism of accelerated sulphur crosslinking of natural rubber $(\mathrm{R}$ - accelerator residue).

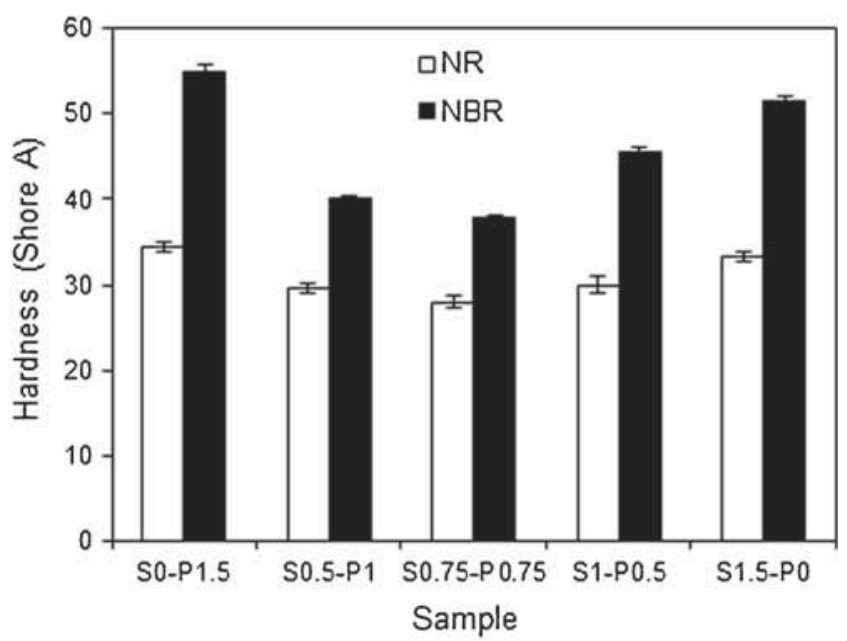

Figure 9. Influence of curing system composition on hardness of composites. lowest cross-link density. As seen in figure 10, the elongation at break of prepared composites also to a certain extent correlates with the dependence of cross-link density. In the case of both type composites, the highest elongation at break is shown by sample S0.75-P0.75 because of low degree of cross-linking. With increasing cross-link density the mobility of rubber chains is more restricted, consequently leading to the decrease of elongation at break. Among all composites, the lowest elongation at break was found to be exhibited by the composite based on NBR cured only with peroxide system (S0-P1.5) with the highest cross-link density.

From figure 11 it becomes clearly evident that the tensile strength of NR-based composites is improved with increasing amount of sulphur or decreasing amount of peroxide in the applied curing systems. The difference between the tensile strength of the sample cured only with peroxide system (S0-P1.5) and the sample cured only with sulphur system

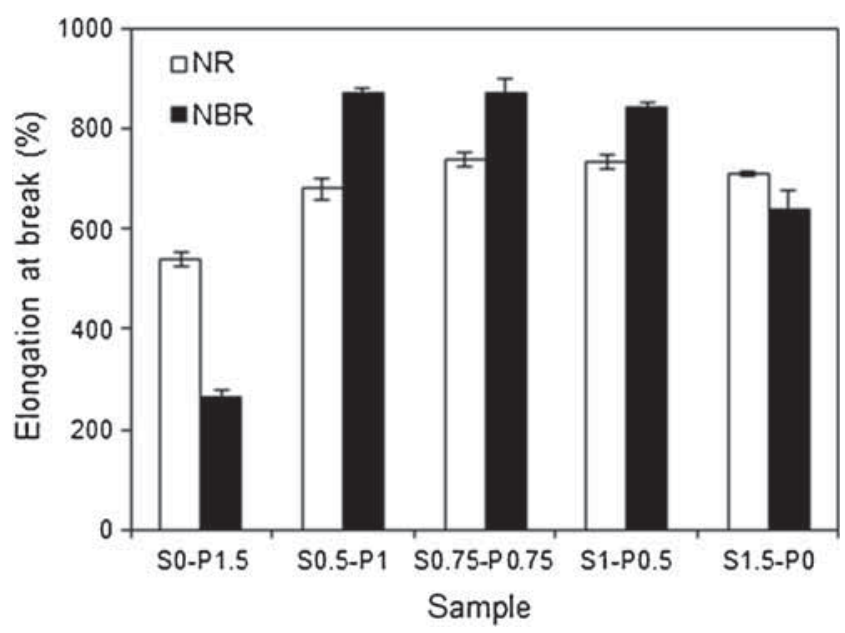

Figure 10. Influence of curing system composition on elongation at break of composites.

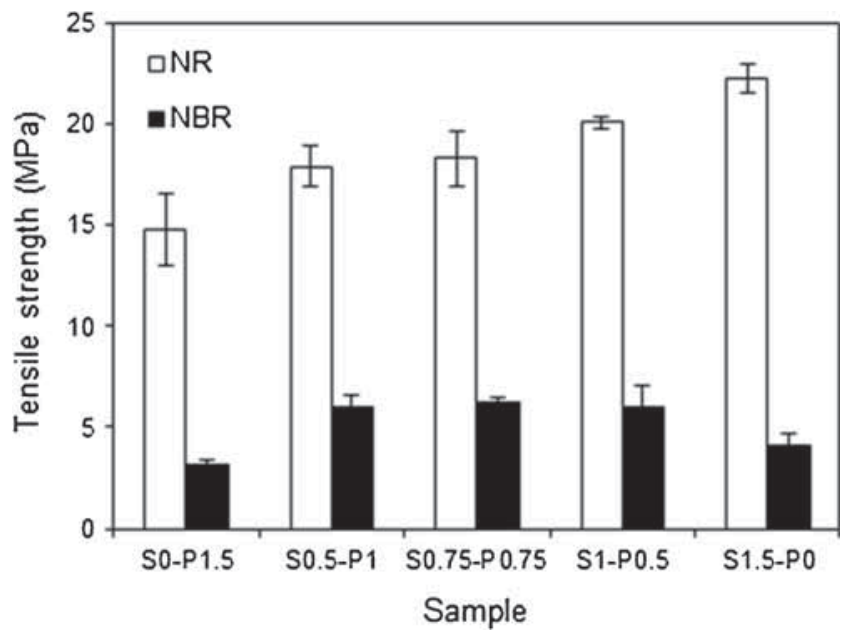

Figure 11. Influence of curing system composition on tensile strength of composites. 
(S1.5-P0) was nearly $8 \mathrm{MPa}$. NR is a crystallizing polymer, which can crystallize spontaneously, but also under an influence of deformation strength (stress-induced crystallization). The crystallization improves intra and intermolecular attractive forces which consequently result in the reinforcement of the rubber [28]. The application of peroxide curing systems leads to the forming of more rigid carbon-carbon bonds between rubber chain segments, while in sulphur-cured elastomers, elastomer chains are crosslinked together by longer and more elastic sulphidic linkages. More rigid $\mathrm{C}-\mathrm{C}$ bonds restrict the mobility and orientation of rubber chain segments in the cross-linked elastomers when they are stretched and subsequently they inhibit the stressinduced crystallization, which imparts high values of tensile strength on composites based on NR. By contrast, more flexible sulphidic bridges make the micro-Brown motion of elastomer chains segments between the cross-links easier which improves the elastic and dynamic properties of composites [14]. Thus, the elastomer chain segments may more easily achieve the conformation needed for crystallization. It can be concluded that the higher the crystallization ability of NR, the higher the tensile strength of composites, as also observed in figure 11. The crystallization of NR is also the main reason for much higher tensile strength of composites based on NR compared with that of composites based on NBR, which behaves as a non-crystallizing elastomer. From figure 11 it is shown that the tensile strength of composites based on NBR is much less dependent on the composition of curing system. The tensile strength of the composite cured only with peroxide system (S0-P1.5) is only slightly above $3 \mathrm{MPa}$, while the tensile strength of the composite cured only with sulphur system reaches the value of $4 \mathrm{MPa}$. The tensile strength of composites with mixed curing systems is enhanced to over $6 \mathrm{MPa}$, while the highest tensile strength is exhibited by the sample cured with equivalent ratio of sulphur and peroxide (S0.75-P0.75). The achieved results point out to some synergistic effect of both curing systems and

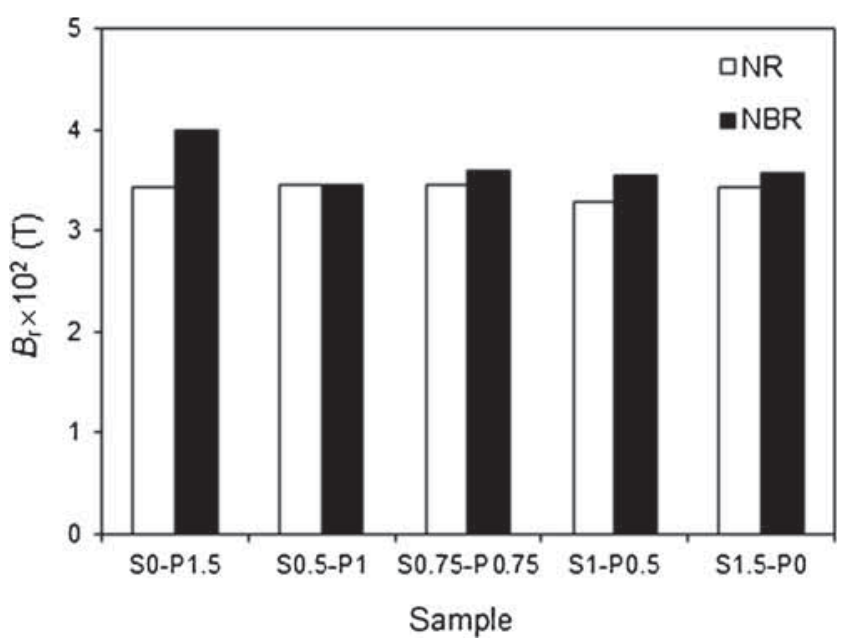

Figure 12. Influence of curing system composition on remanent magnetic induction $B_{\mathrm{r}}$ of composites. demonstrate very promising aspects relating to the preparation of rubber materials with mixed vulcanization systems, especially those based on non-crystallizing synthetic rubbers.

\subsection{Influence of curing systems on thermo-physical and magnetic characteristics}

Elastomers usually have low thermal conductivity and no magnetic properties. The thermal conductivity of ferrites is much higher as they are metal oxides powders and they are manifested to behave as magnetic substances. In some of our works $[18,29]$ it was described that the incorporation of ferrite into rubber matrix imparts magnetic characteristics to the composites considerably and also leads to increased thermal conductivity and thermal flow through them. As in the present study the content of magnetic filler was kept constant in all composites, the main goal was to investigate the influence of the type of rubber matrix and change in the vulcanization systems on the special characteristics.

The most important magnetic characteristics of all permanent magnets is the remanent magnetic induction $B_{\mathrm{r}}$, which represents the value of residual magnetism in the material, when the material is magnetized in the presence of external magnetic field. From figure 12 it is seen that the values of remanent magnetic induction of both type composites move only in a low range independent of the type of curing system applied. Comparing the type of rubber matrix, composites based on NBR seem to have slightly higher values of $B_{\mathrm{r}}$.

A very similar dependence behaviour on the type of curing system is possible to observe also from graphical illustrations of thermo-physical parameters. Both thermal conductivity coefficient $\lambda$ and volumetric heat capacity $C_{\rho}$ of tested composites remained almost constant with the change in vulcanization systems. From figures 13 and 14 it becomes clearly apparent that composites based on NBR exhibit higher values of thermo-physical properties. Higher values of

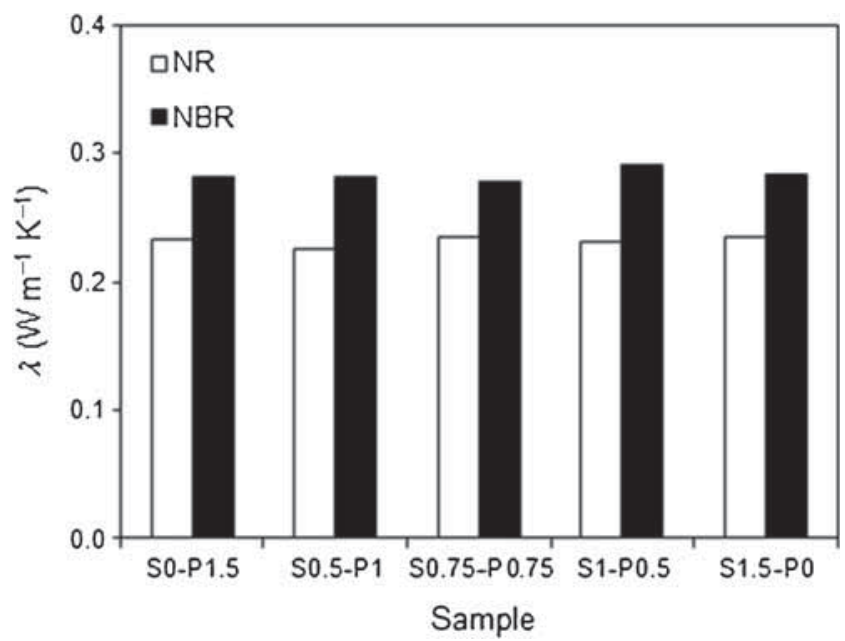

Figure 13. Influence of curing system composition on thermal conductivity coefficient $\lambda$ of composites. 


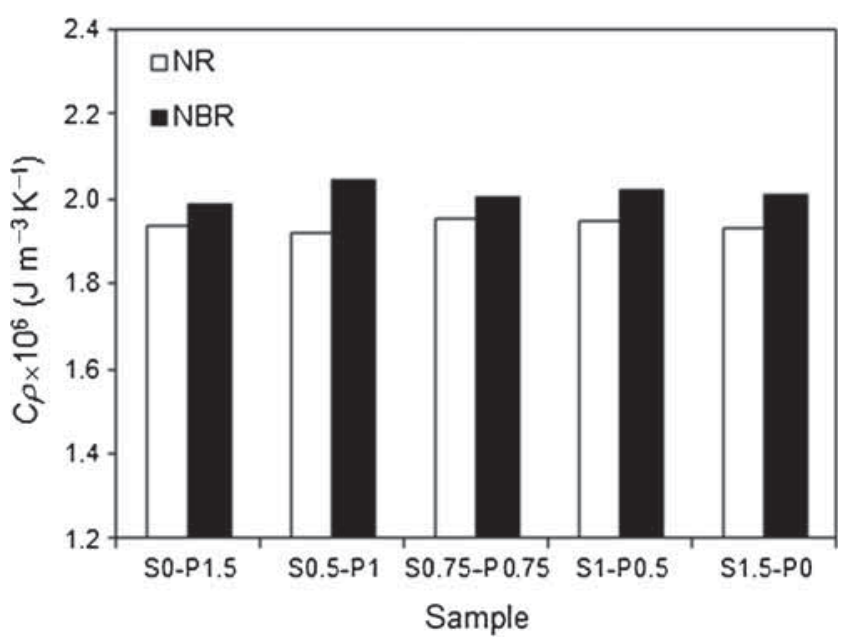

Figure 14. Influence of curing system composition on volumetric heat capacity $C_{\rho}$ of composites.

thermo-physical and magnetic characteristics of composites based on NBR could be attributed to the presence of polar acrylonitrile structural units of NBR, which might be able to contribute to the increased thermal and magnetic flow through the material.

\section{Conclusion}

Magnetic rubber composites were prepared by incorporation of strontium ferrite into rubber matrices based on NR and NBR. Sulphur, peroxide and mixed sulphur/peroxide curing systems were applied in cross-linking of rubber matrices. The aim was to investigate the influence of the type of curing system and rubber matrix on the cross-linking and properties of prepared materials.

The results showed that composites based on NBR exhibited higher cross-link density, while the sample cured only with peroxide system showed the highest one. The values $v$ of both type composites cured with mixed sulphur/peroxide curing systems were lower compared with corresponding composites cured only with peroxide or sulphur curing systems. The hardness and elongation at break of NR- and NBR-based composites are in very close correlation with the change in cross-link density. A different character of dependence on curing system composition was recorded in the case of tensile strength. The tensile strength of composites based on NR was improved with increasing amount of sulphur and decreasing amount of peroxide in the applied curing systems, as a result of increasing amount of longer and more mobile sulphidic cross-links which promote crystallization of NR. On the other hand, in the case of composites based on NBR, the highest tensile strength was exhibited by the sample cured with equivalent ratio of sulphur and peroxide, suggesting some synergistic effect of both curing systems applied in cross-linking of NBR-based rubber materials.
Thermo-physical and magnetic properties of composites were found not to be influenced by the curing system composition. Polar groups of NBR are believed to contribute to the increased magnetic and thermal flow through the material.

\section{Acknowledgement}

This work was supported by the Slovak Research and Development Agency under Contract No. APVV069412.

\section{References}

[1] Wang Y F, Li Q L, Zhang C R and Jing H X 2009 J. Alloys Compd. 467284

[2] Mahmoud K H and Makled M H 2012 Adv. Chem. Eng. Sci. 2350

[3] Li J, Zhang H F, Shao G Q, Chen D, Zhao G G, Gao Z S, Liu J H, Lu J S and Li X B 2015 Procedia Eng. 102 1885

[4] Yadhu K, Shine Ch, Nazeeha U, Smitha T R, Parameswaran P S and Prema K H 2015 Int. J. Chem. Stud. 315

[5] Saramolee P, Lertsuriwat P, Hunyek A and Sirisathitkul C 2010 Bull. Mater. Sci. 33597

[6] El-Nashar D E, Ahmed N M and Agami W R 2013 Mater. Des. 52108

[7] Bellucci F S, de Almeida F C L, Nobre M A L, Rodríguez-Pérez M A, Paschoalini A T and Job A E 2016 Composites Part B 85196

[8] Pattanayak R, Muduli R, Panda R K, Dash T, Sahu P, Raut S and Panigrahi S 2016 Physica B 48567

[9] Tong S Y, Tung M J, Ko W S, Huang Y T, Wang Y P, Wang L Ch and Wu J M 2013 J. Alloys Compd. 55039

[10] Das S, Nayak G C, Sahu S K, Routray P C, Roy A K and Baskey H 2015 J. Magn. Magn. Mater. 377111

[11] Abi S A, Kuruvilla J, Thomas M, Volker A and Sabu T 2003 Eur. Polym. J. 391451

[12] Heideman G, Datta R N, Noordermeer J W M and Van Baarle B 2005 Rubber Chem. Technol. 78245

[13] Koenig J L 2000 Rubber Chem. Technol. 73385

[14] Kyselá G, Hudec I and Alexy P 2010 Manufacturing and processing of rubber, 1st edn (Bratislava, Slovakia: Slovak University of Technology Press)

[15] Sheng Ch, Hu Z, Martin H, Duan Y and Zhang J 2015 J. Appl. Polym. Sci. 132 doi: 10.1002/APP.41612

[16] Dluzneski P R 2001 Rubber Chem. Technol. 74451

[17] Visakh P M, Thomas S, Chandra A K and Mathew A P 2013 Advances in elastomers I: blends and interpenetrating networks (Berlin, Germany: Springer)

[18] Kruželák J, Hudec I and Dosoudil R 2012 Polimery $\mathbf{5 7} 25$

[19] Kruželák J, Sýkora R, Dosoudil R and Hudec I 2015 Compos. Interfaces 22473

[20] Kruželák J, Sýkora R, Dosoudil R and Hudec I 2014 Polym. Adv. Technol. 25995

[21] Kraus G 1963 J. Appl. Polym. Sci. 7861

[22] El-Nemr K F 2011 Mater. Des. 323361 
[23] Shanmugam K V S 2012 Peroxide curable butyl rubber derivatives. $\mathrm{PhD}$ Thesis (Kingston, Ontario: Queen's University)

[24] Akiba M and Hashim A S 1997 Prog. Polym. Sci. 22475

[25] Valentín J L, Rodríguez A, Marcos-Fernández A and Gonzáles L 2005 J. Appl. Polym. Sci. 961

[26] Van Duin M 2002 Kautschuk Gummi Kunststoffe 55150
[27] Chapman A V and Johnson T 2005 Kautschuk Gummi Kunststoffe $\mathbf{5 8} 358$

[28] Basfar A A, Abdel-Aziz M M and Mofti S 2002 Radiat. Phys. Chem. 6381

[29] Kruželák J, Ušaková M, Dosoudil R, Hudec I and Sýkora R 2014 Polym.-Plast. Technol. Eng. 531095 